\title{
From Physical Co-location to Perceived Co-presence: "I feel close to you when I use my mobile"
}

\author{
Antonio Díaz Andrade \\ Auckland University of Technology, New Zealand \\ antonio.diaz@aut.ac.nz
}

\begin{abstract}
Mobile phones represent one of the most pervasive technologies of our time. This technology not only makes possible communication at a distance but also creates a communicative environment that enables the transportation of social life within the space-time system. Since young adults have largely embraced mobile technology for their everyday activities, this research analyses how individuals in the 18-24 years old age bracket realise their social life through mobile phones. The findings of this study conducted in New Zealand show that the use of mobile phones reshapes the young adults' perceptions of their social space-time system. The evidence suggests that, regardless of whether the individuals are the call makers or the call takers when they talk to their loving partners, close family members and close friends, a subjective understanding of co-presence overshadows their physical co-location. Individuals perceive to be closer to their communication partners than to those in their corporeal proximity.
\end{abstract}

Keywords : Co-presence, space-time system, mobile phones, young adults, communicative environment, social life 


\section{Introduction}

What distinguishes human beings from animals above all is their communicative capacity. It allows us to turn existing information "into new insights, symbols, or representations meaningful to others with whom we converse" (Benkler, 2006, p. 52). For centuries, proximity was a requirement to make possible oral communication between two or more individuals. It was not until the beginning of the ninetieth century, with the emergence of the electric telegraph first, and then towards the end of the ninetieth century, with the appearance of radio and telephone technologies, that the communicative capacity between individuals at a distance was made possible. These technologies evolved further to the point that not only realised the communication between distant but also movable persons: mobile phone technology. It liberated both the senders and receivers from being stationary in order to establishing the communication. These days we enjoy an ample 'communication repertoire' (Haddon, 2005) and can easily jump from face-to-face interaction, to communication through what it is called now a fixed-line telephone, to phone calls and short message service (SMS) via mobile phones, not to mention different means of communication through the Internet. We are living an era where convergent technologies facilitate communication and allow remote interaction - cf. 'technological accordances' (Wellman et al., 2003). And the essential technological affordance of mobile phones is ubiquity (Castells et al., 2007).

Since its commercial introduction in the early 1990s, mobile phone technology has expanded rapidly across the globe. The latest available figures show that mobile phone subscriptions have reached 6.8 billion worldwide, which is equivalent to a global penetration of $96 \%$ (International Telecommunication Union, 2013). A closer inspection of this upward trend of mobile phone users reveals that young adults are the most enthusiastic age group. In the
United States, the mobile phone users between 18 and 24 years old are regarded as "the cellular generation", who consider the cell phone as part of their everyday lives (comScore, 2007). In New Zealand, where this study was conducted, in the 15-24 years old age bracket, mobile phone ownership for personal use was 93\% as December 2009 (Statistics NZ, 2010), while - at the time of writing this paper $30 \%$ of Internet users connect via their mobile phones (Statistics NZ, 2013). The overall mobile phone penetration in New Zealand reached $111 \%$ in June 2012 (Commerce Commission, 2013).

Although some disparities still persist in terms of mobile penetration, there is no doubt that mobile phones are now a common means of communication. These days, it is not unusual to see individuals using their mobile phones while doing their routine activities. This extended use of mobile phones now includes circumstances and places where the social conventions may consider the use of mobile phones inappropriate such as in the movie theatre, classroom or church. The Time Mobility Poll, an international survey, which included almost 5000 people of different age groups and income levels in Brazil, China, India, Indonesia, South Africa, South Korea, the United Kingdom and the United States, shows that a quarter of the respondents check their mobile phones every 30 minutes, while $20 \%$ do it every 10 minutes (Gibbs, 2012). Moreover, invariably in every country except for Indonesia, more than $20 \%$ of the respondents admit that their mobile had come at times between them and their spouses - in China and India the percentage goes over $50 \%$.

These figures corroborate the fact that mobile users are almost always available to interact with their contacts. Mobile phones have made users "snails in the sense that [they] carry [their] relational house in the back" (Fortunati, 2005, p. 217). As a consequence, a new technology-mediated communicative environment emerges, where interacting with the physically absent 
others while on the move is possible. Corporeal proximity is no longer needed for the interactions to take place, while the time of these interactions is no longer dependent on the location of the communication partner. For instance, parents who need to contact their children who are on a school trip can reach them through their mobile phones at any time - the need of ringing the school fixed number, available during school hours only, and then waiting for relaying the call to the location of the school trip has disappeared. Katz and Aakhus (2002) coined the word "apparatgeist" to emphasise the notion of perpetual contact, which expresses the role personal communication technology plays in people's lives. This communicative environment produces new interpretations of space and time. Mobile phone users, while still bounded within a space-time system, somewhat feel detached from those in their vicinity and become immersed in a copresent relation with those at a distance. This phenomenon has yet to be fully understood.

It is against this background that this study aims at understanding how mobile phone users reshape their interpretations of space and time. In order to capture these reshaped interpretations, this study investigates mobile phone users' perceptions of detachment from their physical surroundings and closeness to their communication partners. These perceptions are simultaneously examined when the mobile phone users are call makers and call receivers in relation to three different groups of communication partners: loving partners, close family and friends. Specifically, the research questions guiding this study are:

Are there differences in the perception of co-presence between individual's roles as call makers and call receivers when they use their mobile phones?

Are there differences in the perception of co-presence among different subjects who people mostly interact with through mobile phones?

This paper is organised as follows. The next section presents a theoretical discussion of the space-system, with a particular focus on how mobile phones are used within this system. The following section elaborates on how social interaction through mobile phones shapes the communicative environment. The next section introduces and explains the concept of co-presence. The next section describes the methodological procedures applied in this study, followed by a section where the analysis is presented. The last section discusses the results of the analysis and presents the conclusions of this study, along with its limitations and opportunities for future research.

\section{The Space-time System}

The presence of information and communication technologies, including mobile phones, has produced a time-space compression of everyday activities (Gibbins and Reimer, 1999). In the same way that mobile phones make possible stretching work time and employees can be contacted for work-related purposes while they are at home, mobile phones also make possible for parents, friends or partners contacting individuals while they are, say, in office or at university. In this sense, time and space provide the conceptual foundations for the subsequent discussion on the transition from physical co-location to perceived copresence when individuals use their mobile phones.

Before introducing the temporal element, the distinction between place and space needs to be explained. On the one hand, place is more than just the physical location where actors have face-to-face encounters. Places are socially constructed and every place reflects its own social practices (Harvey, 1993) - e.g., a stadium, where thousands of non-acquaintances follow certain rituals in a relatively coordinated fashion. On the other hand, space is not 
only a social construction; it explicitly recognises the relationship among absents - e.g., the stock market, where investors transact considerable amounts of money without necessarily being physically present.

The co-existence of social interactions constitutes the social space (Barker, 2003). Therefore, understanding how human activity occurs in space, while paying attention to the dynamic nature of social relations, is critical to analyse social life (cf. Giddens, 1984). Space is where social practices take place; it "is the expression of society [and] provides the material support of time-sharing social practices" (Castells, 2000, pp. 440-441). Time-sharing practices should not be interpreted as activities taking place in contiguity only since coordinated social activities can be performed at a distance too. Absent actors can still make manifest their status and power in a 'spaceless place' by using new technological tools (Ogden, 1994). For instance, faculty members project an image of who they are by including their publications, presentations and teaching areas on their institutional websites. In the same way, a teenager portrays herself as an attractive person on a social network site by showing her association with fashionable brands. Furthermore, it is the social proximity - rather than the physical one - of the network of relationships what defines 'social time' (Green, 2002).

Time is a "symbolic nexus around which coalesce issues of order" (Dubinskas, 1988, p. 3). The essence of this statement explains how humans organise their lives in a chronological framework. For instance, project activities are organised on a calendar basis. Temporal arrangements are deeply internalised in human lives. They are not restricted for organising the activities an individual performs on a daily basis (e.g., lunch time). Temporal arrangements also entail social coordination (e.g., office hours) and even historical references (e.g., the Enlightenment Era).
Both physics and social sciences recognise the nature of the inextricable relationship between space and time. Physics teaches us that time cannot be separated from and independent of space. They both conform a four-dimensional object called space-time (length, width and height define space), whose points are events in time (cf. Hawking and Mlodinow, 2005). Sociology also observes that space and time are interlinked; they provide the framework to understand social action (Harvey, 1990). Social events take place in the space-time system. Changes in any of these pair of elements necessarily affect the other one (Giddens, 1990).

Four decades ago, Toffler (1971) observed that the duration of our relation with things, places, people, organisations and ideas were shrinking. He challenged us to leave behind what he called a "Newtonian view of the universe" (p. 58), whereby time goes by over a fixed place, and embrace an "Einsteinian" approach, where the relationship between humans and the outer world is of the transient nature. The notion of 'present-extensive', which reflects the generalised perception of vanishing distinction between yesterday and tomorrow, is especially pronounced in today urban environments (García-Montes et al., 2006). For instance, the real estate agent, continuously compiling and listing properties as well as organising the coming together of old and new sellers and buyers, exemplifies this situation - the always-changing circumstances organise the real estate agent's activities on a daily succession.

As I explain next, the coordination and execution of social activities through mobile phones contributes to blur the distinction between here and there as well as between yesterday and tomorrow.

\section{The mobile phone in the space-time system}

Both the traditional fixed-line telephone and the mobile phone are technologies designed to make possible the communication among individuals physically separated, rendering 
distance insignificant. As Gillespie and Williams (1988) reasoned: "When the time taken to communicate over 10,000 miles is indistinguishable from the time taken to communicate over 1 mile, then 'time-space' convergence has taken place at a fairly profound scale" (p. 1317). While the written text and the fixed-line telephone make possible action at distance, it is the mobile phone the one that epitomises this attribute (Cooper, 2002). The ways mobile phones are used reveal an evolution from mobility features to connectivity features. Ubiquitous connectivity becomes the fundamental process that redefines the space where social interactions take place (Castells et al., 2007) - cf. Gergen's (2002) notion of 'perpetual connection'.

Although mobile technology makes possible the extension of normal human hearing sense, its ubiquitous connectivity also makes possible the two worlds of the spacetime system - the vicinity and the remote as well the arrangement of subsequent events - intersect (Schegloff, 2002). The interaction among initially remotely located communication partners, facilitated by the communication networks, can carry on as they come physically closer. The massive protests in the Philippines in 2001, when thousands of demonstrators were summoned in central Manila via text messages to express their disapproval against corrupted practices in government (Rheingold, 2002), illustrates this point.

Furthermore, the mobile phone is unique in making possible 'micro-coordination' (Ling, 2000). That is, the precise adjustments of activities across spatial distance while people are on the move. A case in point is Al Gore's withdrawal of his early concession to George W. Bush in the aftermath of the 2000 presidential election in the United States once his campaign manager learnt via mobile phone that the margin between the two candidates was slim while Gore and his entourage were on their way to the planned public concession (Norris, 2001). Indeed, mobile phones make possible last minute variations of pre-planned activities.
Although the consequences might not be as dramatic as the one previously illustrated, micro-coordination among young mobile phone users occur every day. When they agree to meeting up, say in a mall, it is not until they are in the shopping centre that they contact each other to determine the exact location of the imminent gathering - cf. 'flexible rendezvousing' (Castells et al., 2007).

Therefore, the possibility of social interaction is not restricted to the mobile phone owner with someone else in a distant location but could also involve those in the vicinity. Green (2002) claims that "social space and time are extended [and simultaneously] remain locally continuous" (p. 291). The mobile phone serves not only to communicate with people at a distance but also to communicate something to people in the immediate physical locale. The display of mobile phones and the act of making/taking mobile phone calls are expressions of the users' lifestyles and the speeds they live their lives (Bassett, 2000). Alternatively, as it has been observed, the mobile phone can be used for stagephoning - that is, maintaining fictitious conversations in order to impress the surrounding audience with a striking topic or to extend one's personal space if one does not want to be interrupted by people in the surroundings (Plant, 2002). Along these lines, Weilenmann and Larsson (2002) have identified two forms of social interaction by sharing mobile phones: 1) "minimal form of sharing", when only the transmitted information is shared - e.g., showing a text message on the small screen to associates who are in the surrounding area; 2) "handson sharing", involves the phone actually being handled by more than one person e.g., allowing someone else to take a call on one's mobile phone.

Furthermore, the way mobile phones are used goes beyond just a functionalist approach. It is the social and cultural context what defines how mobile communication is managed. After tracing mobile phone use among youth Japanese, 
Ito (2005) reveals that instead of disrupting the existing social norms in different places, mobile users create their own communicative space that accommodates to the existing, rather rigid, restrictions in place. The use of non-vocal functions of mobile phones - i.e., texting - in the classroom, where mobiles are not allowed, exemplifies the adaptive process of establishing a communication channel within an uninviting environment. Beyond the understandable restrictions that prevent verbal communication among students using their mobile phones in a classroom setting, there is growing evidence that individuals are increasingly turning to their mobile phones in less restrictive environments instead of giving consideration to those in their surroundings - see the works of Castells et al. (2007), Middleton (2007), Plant (2002) and Turkle (2011).

\section{The Communicative Environ- ment}

It is recognised that mobile phones reflect the user's personal tastes conforming gratification purposes (Katz and Sugiyama, 2005) and can satisfy esteem and expression needs (van Bijljon et al., 2008). For some young people not owning a mobile is equivalent to not being part of the social network because the exchange of information continues well beyond the contiguous and regular interaction with their circle (Ling, 2000). For instance, when I asked my then 17-year old son why he used his mobile phone to maintain contact with his friends with whom he had just shared most of the day at school, his natural answer was: "There is much going on during after-school hours and I want to keep up with my mates". Indeed, it seems that owning a mobile phone became a mix between sentiment, interest and obligation (Gergen, 2002).

Examples of how mobile phones are changing social practices among young adults are plentiful. Since this topic attracted my interest as a researcher, I became more attentive of certain social practices that involved the use of mobile phones among young adults. For instance, some time ago, while I was waiting for the bus, I saw a girl at the bus stop, who was talking on her mobile. We both rode the same bus; moreover, we sat together. She continued the phone conversation until I got off the bus about 30 minutes after I spotted her for the first time. She looked absolutely absentminded of what was happening in her surroundings. In some other occasions, I could overhear mobile phone users informing their interlocutors about the points we were passing by as the bus was moving along, coordinating activities for the upcoming weekend and even once I could hear a young man complaining about his partner's lack of affection towards him. They all seemed oblivious of people in their proximity. As for me, even though I could hear just one side of the conversation, it was enough for me to figure out the overall plot of the talk. On this matter, Plant (2002) reports that overhearing just one side of the communicative partners can lead to frustration for missing the other side of the conversation. Far from managing their voice tone and volume, my fellow bus passengers were fully engaged into a private environment when using their mobile phones simply ignoring who were in their vicinity. The other passengers and I had just not been invited to their private conversations and whether we became knowledgeable or not of the topics they were talking about was not of their concern at all. The situations described here reveal the freedom of holding a more or less intimate conversation in front of strangers. Their inner self become, to some extent, public blurring the line between "front-stage" and "back-stage" (cf. Goffman, 1971). In the conflicting situation where the mobile phone users had to operate in two different environments, the anecdotal evidence suggests that the distant and technologymediated environment overtook the tangible and physical surrounding. 
The aforementioned observations suggest that young adults have integrated the use of the mobile phone into their routine - cf. Green's (2002) "rhythms of mobile use in everyday life"(p.285). Hence, an examination of how young adults manage and adjust their social practices by using their mobile phones in the space-time system is needed. The ultimate goal is to uncover and get a preliminary understanding of how the communicative environment engenders the transition from co-location - interaction with others in the vicinity - to co-presence - interaction with others across distance - when using mobile phones.

\section{Co-presence}

The central argument of this study is that the communicative environment in the space-time system modifies mobile users' perceptions of corporeal presence. The technology-mediated communicative environment detaches the individual from their co-located interaction to become immersed in a co-present relation with those at a distance - cf. Gergen's (2002) "absentpresence".

Co-presence can be broadly defined as a human perception of being close to others who are not in corporeal proximity. Previous literature concurs in the conceptualisation of co-presence. Zhao (2003) states that "the sense of copresence involves the individual's the perceptions and feelings of being with others" (p. 453). Recently, Campos-Castillo and Hitlin (2013) put forward the notion of co-presence as "the perception of mutual entrainment between actors" (p. 169). Nowak and Biocca (2003) emphasise that co-presence "solely refers to a psychological connection to and with another person" (p. 482). These definitions have two conceptually common elements that make them relevant for this study. First, they all explicitly recognise that co-presence, although technology mediated, pertains to human-to-human interaction only - e.g., computer-mediated communication, phone communication. Unlike other studies, whose focal point is on the individual interacting with and immersed in computer-generated environments (Steuer, 1992), the aforementioned authors exclude human-tocomputer interaction in their conceptualisation of co-presence. Second, they all highlight that it is the perception of being close to the absent other what matters. The physical proximity becomes secondary to the perceived proximity of the communication partner: "a person may be on the telephone to someone twelve thousand miles away and for the duration of the conversation be more closely bound up with the responses of that distant individual than with others sitting in the same room" (Giddens, 1991, cited by Campos-Castillo and Hitlin, 2013, p. 170).

Among the six conceptualisations of presence that Lombard and Ditton (1997) put forward, there is one that resonates well with the definitions of co-presence presented in the previous paragraph: transportation. Co-presence as transportation reveals two elements. The first one is the closeness the individual perceives to his/her communication partner at the other end of the line. The second one is the perceived detachment from the individual's physical surroundings. These two elements are complementary in shaping the state of co-presence. In this sense, copresence becomes a social construction where the communication partners experience the feeling of being together and, simultaneously, they cut off their links to what is going on in their contiguous locations. Previous research on copresence suggests that experiencing nearness of communication partners - in other words, the feeling of being emotionally together - can be achieved by using telephone technology (Ijsselsteijn and Riva, 2003). Similarly, the examples presented in the previous sections of this paper illustrate instances where the individual feels completely removed from what is going on in his/her surroundings. As Fortunati (2005) articulates, "the stranger becomes the 
depository of the most intimate secrets and the most delicate information" (p. 216).

Consequently, the analytical focus of this research is on the mobile phone as a device, which makes possible the communication among socially and affectively interconnected individuals. With the introduction of mobile phones, the wish for telecommunication on the go was eventually realised. It made possible to be independent of the fixed-line telephone, giving the opportunity of moving around while talking on the phone (the only restriction is now given by the area of coverage, although satellite phones make possible the communication from virtually every corner of the planet). Furthermore, mobile phones are used now not only while moving between two different points but also while staying in determined places where one has no access to a fixed telephone. This observation reflects the shift from the notion of mobility to the more encompassing idea of ubiquity when using mobile phones (Castells et al., 2007). As a consequence, the place where the communication - either stationary or on the move - now takes place thanks to the mobile phone may include diverse locations from cars and public transportation to home, office, classroom, shop and church to urban streets and rural farmlands.

Having discussed the changes on the space-time system introduced by mobile technology, described how the social interaction through mobile phones shapes the communicative environment and introduced the notion of co-presence, I can proceed now to present the hypotheses to be tested. They are intended to answer the research questions put forward early.

It is assumed that the perception of being with the communication partner is not influenced by the condition of being either a call maker or a call receiver. It is expected that both parties are equally immersed with one another when using mobile phones. Therefore, the first hypothesis is formulated in the following terms:

\section{$H_{1}$ : There are no differences in the perception of co-presence between call makers and call receivers}

Communication using mobile phones is undertaken not by isolated individuals but by individuals who are part of a larger context. The level of interaction individuals have in both face-to-face and technologymediated communications affects the level of co-presence (Riva and Mantovani, 2000). The degree of affection and familiarity or the expectation the individual has on the communication partner can make the technology-mediated conversation more or less intense. Since it is assumed that individuals communicate most often with those who they are affectively close to, something that was eventually corroborated once the data collection has been completed, the intensity of the technologymediated conversation and, consequently, the level of co-presence is high. Therefore, the second hypothesis is formulated in the following terms.

\section{$\mathrm{H}_{2}$ : There are no differences in the perception of co-presence among different subjects who young adults mostly interact with through mobile phones}

\section{Methodology}

For analysing the notion of co-presence, two proxy indicators were produced: perceived closeness to the communication partner (designated here as CloTal) and perceived detachment from the physical surroundings (designated here as DetPhys). These two proxies derive from the two elements of co-presence as transportation discussed earlier (Lombard and Ditton, 1997). Thus, CloTal refers to the closeness the individual perceives to his/her communication partner at the other end of the line. DetPhys denotes the perceived detachment from the individual's physical surroundings. 
Although self-reporting - in this case the experience of co-presence - may affect the nature of data (cf. Field, 2009), the fact that these two elements are subjective make them suitable to be reported only by the individuals experiencing them (Schubert et al., 2001). Along the same lines, Riva and Mantovani (2000) convincingly argue that the criterion of the validity of co-presence can only be given by the social context within which actors exploit the technological affordances rather than simply attempting the replication of physical conditions - a condition hardly achievable and of uncertain outcome. Thus, participants of this study were asked to quantify these elements of co-presence when using mobile phones.

These two elements of co-presence became the dependent variables in the conducted multiple analysis of variance (MANOVA). They were measured at the interval level using a Likert-scale from 1 to 5 , where a score of 1 represented a strong agreement and a score of 5 represented strong disagreement. The perception of closeness to the communication partner was measured using the following statement: "When I talk to someone through the mobile phone I use, I feel that my communication partner and I are together". The perception of detachment from the physical surroundings was measured using the following statement: "I feel comfortable talking about private matters on a mobile phone in front of strangers who happen to be next to me".

Data was collected between November and December 2009 using an anonymous survey applied to individuals, users of mobile phones, aged between 18 and 25 years old. The setting of this research was a New Zealand university and the participants were all students - $90 \%$ of them reported to be full-time students. The survey was personally distributed by the researcher in eight different classrooms to those individuals who agreed to participate. A total of 111 questionnaires were obtained. However, only 81 were retained to be included in the analysis. Ten questionnaires were excluded because they were incomplete, 11 because the groups who were identified as those who the participants call to or receive the calls from most often were substantially small (for instance, only one participant declared that his/her mobile was mostly used for communications related to medical issues, plus some other cases that are explained below) and just a few cases that showed inconsistent answers.

Table 1 presents participants' demographic information (valid responses only).

\begin{tabular}{|c|c|c|c|}
\hline & Number & Percentage \\
\hline \multirow{2}{*}{ Gender } & Female & 52 & $64.2 \%$ \\
\hline & Male & 29 & $35.8 \%$ \\
\hline \multirow{2}{*}{ Main occupation } & Student & 74 & $91.4 \%$ \\
\hline & Employee & 7 & $8.6 \%$ \\
\hline \multirow{2}{*}{ Marital status } & Single & 68 & $84.0 \%$ \\
\hline & Married or de facto relationship & 13 & $16.0 \%$ \\
\hline \multirow{2}{*}{ Mobile phone was } & Bought or received as a gift & 79 & $97.5 \%$ \\
\hline & Provided by employer & 2 & $2.5 \%$ \\
\hline \multirow{3}{*}{ Mobile phone plan } & Pre-paid & 66 & $81.5 \%$ \\
\hline & Post-paid & 13 & $16.0 \%$ \\
\hline & Do not know & 2 & $2.5 \%$ \\
\hline
\end{tabular}




\begin{tabular}{|l|l|l|}
\hline Table 2: Group sizes for each of the treatment groups \\
\hline \multirow{3}{*}{ Most calls on the mobile phone are made to } & Loving partner & 26 \\
\cline { 2 - 3 } & Close family & 33 \\
\cline { 2 - 3 } & Friends & 22 \\
\hline \multirow{2}{*}{ Most calls received on the mobile phone are from } & Loving partner & 25 \\
\cline { 2 - 3 } & Close family & 29 \\
\cline { 2 - 3 } & Friends & 27 \\
\hline
\end{tabular}

An inspection of the data revealed no bias in the participants' responses in terms of demographic characteristics shown in Table 1. That is, gender, main occupation, marital status, whether their mobile phones were bought, received as a gift or provided by employer, or the type of mobile phone plan does not influence who the participants call the most or who call the participants the most. In addition, it is worth noting that 81.4 per cent of the participants (66 out of 81) whose responses were deemed valid agreed or strongly agreed that not having a mobile phone would turn their lives into a nightmare. This resonates with the results of the aforementioned international Time Mobility Poll (Gibbs, 2012), where 74 per cent of the participants in the United States declared that could not go for more than one day without their mobile phones, while three quarters of those between 25 and 29 years old across the countries where the survey was conducted declared that they take their mobile phones with them for sleeping.

Having identified the dependent variables of this MANOVA study, the next step in the analytical procedure was to identify the treatment groups that were hypothesised to influence the two elements of co-presence. Accordingly, participants were asked to indicate who they call most often using their mobile phones and who they get phone calls from most often on their mobile phones. In both cases, three distinctive groups were identified: loving partners, close family members and friends ${ }^{1}$. This finding

\footnotetext{
${ }^{1}$ Eleven out of the 111 participants indicated that the calls they received / made the most were work-, school- or medical-related. Because of their small number compared to the already identified three
}

confirmed the preliminary assumption that individuals communicate most often with those who they are affectively close to. Thus, for the purpose of this study, these three categories were included in the analysis and considered as the treatment groups (independent variables). Table 2 shows the groups sizes for both who the participants called the most and who their most frequent callers were.

The research objective of this study is to compare these treatment groups and observe the effect they have simultaneously on both the perceived closeness to the communication partner and the perceived detachment from the physical surroundings when talking on the mobile phone. The following variate represents this MANOVA study:

$$
Y_{1}+Y_{2}=X_{1}+X_{2}+X_{3}
$$

Where the dependent variate, co-presence, is given by:

$\mathrm{Y}_{1}$ : perceived closeness to the communication partner (CloTal)

$\mathrm{Y}_{2}$ : perceived detachment from the physical surrounding (DetPhys)

And the independent variables, in this case the treatment groups, are represented by the communication partners:

main groups, these responses were not included in the analysis. 


$$
\begin{aligned}
& X_{1} \text { : loving partner } \\
& X_{2} \text { : close family } \\
& X_{3} \text { : friends }
\end{aligned}
$$

The treatment groups were assembled under two conditions depending on the role of the participants: call makers and call takers.

\section{Analysis}

The sample size of 81 is well above of the recommended at least ten observations per variable to avoid overfitting the data (Hair Jr. et al., 1998). In addition, not only is the number of observations per cell larger than the number of dependent variables (i.e., perceived closeness to the communication partner and perceived detachment from the physical surroundings) but also the number of observations per group exceeds the recommended 20 (Hair Jr. et al., 1998). Although having an equal cell size would have been an ideal situation, it is not an essential condition to proceed with the analysis. As can be observed in Table 2, the group sizes are not equal but are very similar. In addition, there are no instances where the ratio between the smallest group - that is, the calls made to friends (22) - and the largest group - that is, calls made to close family (33) - exceeds the recommended threshold of $1: 1.5$. This minor different cell size was alleviated during the analysis by using the SPSS adjustment for unequal sample sizes (Field, 2009) - i.e., Type 3 sums of squares. Moreover, having more than 20 observations per group makes the test robust to deviations from multivariate normality, which was not a problem in this study as is explained below.
Furthermore, the obtained sample size was enough for achieving a statistical power of 0.80 for medium to large effect sizes (Hair Jr. et al., 1998).

\section{Testing the Assumptions}

It needs to be explained that since participants were asked to answer questions as call takers and call makers, the assumptions of normality, homoscedascity and equality of covariance matrices had to be tested for each of these roles. In addition, the assumption of independence of observations had to be met since it is a critical assumption of MANOVA. For reasons of space, the test of the assumptions for multivariate analysis presented here only shows the role of the participants as call takers, which has been identified for the analysis purpose as RecCal (which stands for received calls). The same procedure was followed when the participants were the call makers (MadCall for made calls). The results in both cases were similar.

The first assumption to be checked was normality of the dependent measures (i.e., closeness to the communication partner and detachment from physical surroundings). Histograms (not shown here) of the dependent measures within each treatment group - for both situations when the participants were the call takers and call receivers - were produced in order to verify univariate normality. A visual inspection did not reveal problems of non-normality. In order to verify multivariate normality, Q-Q plots were produced - see Figure 1. No problems of non-normality were found. 

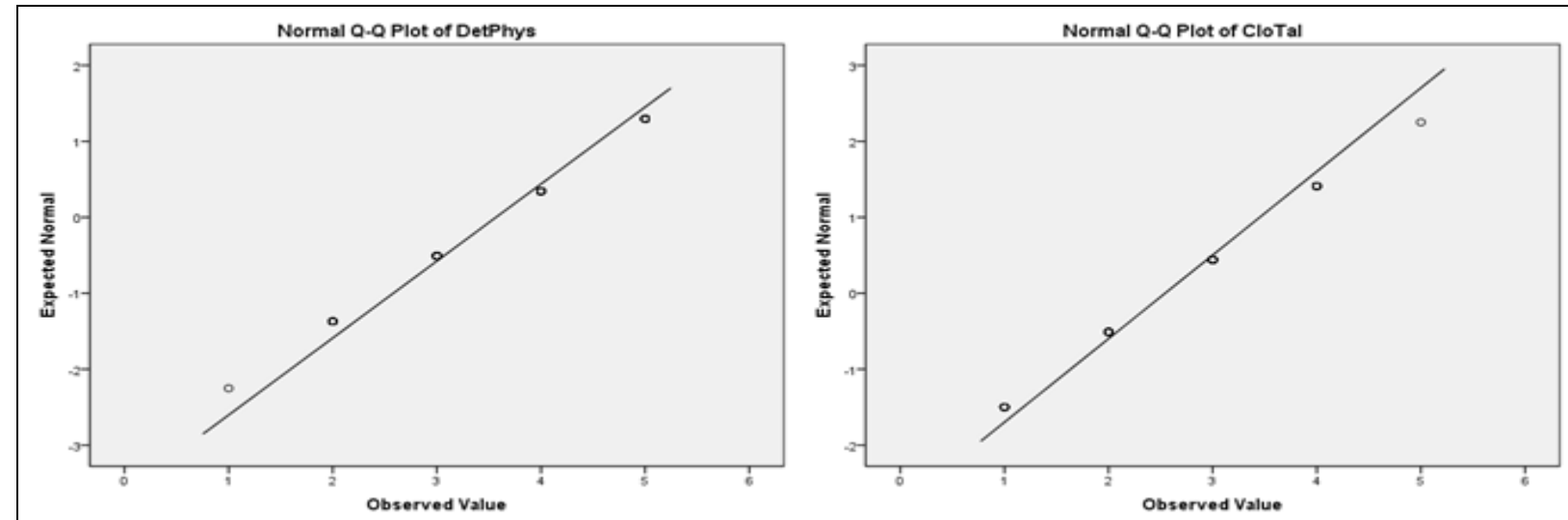

Figure 1: Normality plots for the dependent variables

The univariate tests of equality of variances for each of the dependent variables shows that the homogeneity of variance has been met - see Table 3. For the perception of physical detachment from the surroundings, the variances were equal for the three conditions, $\quad F(2,78)=0.461$, non-significant $(p=0.632)$. Similarly, for the perception of closeness to the communication partner, the variances were equal for the three conditions, $\quad F(2,78)=0.447$, non-significant $(p=0.641)$.

\begin{tabular}{|c|c|c|c|c|c|}
\hline & & Levene Statistic & df1 & $\mathrm{df} 2$ & Sig. \\
\hline DetPhys & Based on Mean & 0.461 & 2 & 78 & 0.632 \\
\hline CloTal & Based on Mean & 0.447 & 2 & 78 & 0.641 \\
\hline
\end{tabular}

Similarly, the assumption of equality of covariance matrices was verified by the Box's test. This test is particularly important since, as it has been explained earlier, the group sizes are slightly different. It was found that the variance-covariance matrices are the same in all three groups - calls received on mobile phones from loving partners, close family and friends $(p=0.975)$. A similar result was obtained when the participants were the call makers.

In order to achieve independence of observations, the participants, all of them university students, were not related to each other (other than being classmates). In addition, every participant belongs to one treatment only. In other words, they identified one group only (either loving partners, close family members or friends) as the most frequent mobile phones calls they made or received.
Since co-presence is made of two proxy indicators only, its reliability was assessed through the use of correlation matrix (Kennedy, 1998). No problems of multicolinearity were found between CloTal and DetPhys: $r=0.140, p$ (one-tailed) $=0.107$. Validity of the notion of co-presence is given by content validity insofar the two proxy indicators used in this study cover its conceptual components: perceived closeness to the communication partner and perceived detachment from the physical surroundings (Lombard and Ditton, 1997).

\section{Model Estimation and Overall Fit}

The next step was to estimate the MANOVA model and assess the overall fit. The purpose of the analysis was to determine whether there were differences among the treatment groups or not. 
Since participants were asked to report on both perceived closeness to their communication partners and perceived detachment from their physical surrounding, the condition under examination constituted a repeated-measure analysis - the same group of participants were asked to rate two different scores (Field, 2009). Thus, the MANOVA analysis examined whether or not there was a significant effect of the independent variables (i.e., when the participants received calls from and made calls to their loving partners, close family and friends) on both perceived closeness to their communication partners and perceived detachment from their physical surrounding.

The multivariate test indicates that there was no significant effect of the independent variables on the dependent variables. Thus, it can be inferred that the participants' roles (i.e., call makers and call takers) and communication partners (i.e., loving partners, close family members and friends) do not have a significant effect on the variate formed by perceived closeness to communication partners and perceived detachment from their physical surrounding.

Following the aforementioned result, the next step was to analyse whether or not there were differences on participant's perceived closeness to their communication partners as well as perceived physical detachment from the surrounding depending on their roles (i.e., call takers and call makers) and communication partners (i.e., loving partners, close family members and friends) separately.

The first analysis was done when the participants were the call takers (RecCal). The results indicate that there were no significant differences between those who receive calls from their loving partners, close family members and friends in terms of their perceived closeness to their communication partners and their perceived physical detachment from the surroundings. As shown in Table 4, Pillai's trace $(p=0.409)$, Wilk's lambda $(p=0.411)$, Hotelling's trace $(p=0.413)$ and Roy's largest root $(p=0.160)$ are all non-significant.

\begin{tabular}{|c|c|c|c|c|c|c|}
\hline \multicolumn{2}{|c|}{$\begin{array}{c}\text { Table 4: Model estimatio } \\
\text { Effect }\end{array}$} & Value & $\mathrm{F}$ & Hypothesis df & Error df & Sig. \\
\hline \multirow{4}{*}{ RecCal } & Pillai's Trace & 0.050 & 1.002 & 4.000 & 156.000 & 0.409 \\
\hline & Wilks' Lambda & 0.950 & $0.998^{\mathrm{a}}$ & 4.000 & 154.000 & 0.411 \\
\hline & Hotelling's Trace & 0.052 & 0.994 & 4.000 & 152.000 & 0.413 \\
\hline & Roy's Largest Root & 0.048 & $1.875^{b}$ & 2.000 & 78.000 & 0.160 \\
\hline
\end{tabular}

This is an interesting yet not completely unexpected result based on the theoretical discussion explained earlier in this paper. There is strong evidence that who the caller is has no significant effect on both the perception of physical detachment from the surrounding and the perception of closeness to the communication partner.

A similar analytical procedure was conducted when the participants took the role of call makers (MadCal) and the results were comparable to the ones obtained when the participants were the call takers. Again, it can be concluded that regardless of whom the participants call (loving partner, close family member or friend) has no significant effect on both the perception of detachment from the physical surrounding and the perception of closeness to the communication partner. As shown in Table 5 , Pillai's trace $(p=0.722)$, Wilk's lambda $(p=0.725)$, Hotelling's trace $(p=0.727)$ and Roy's largest root $(p=0.367)$ are all nonsignificant. 
Table 5: Model estimation (when the participants were the call makers)

\begin{tabular}{|c|c|c|c|c|c|c|}
\hline \multicolumn{2}{|r|}{ Effect } & Value & $F$ & Hypothesis df & Error df & Sig. \\
\hline \multirow{4}{*}{ MadCal } & Pillai's Trace & 0.026 & 0.519 & 4.000 & 156.000 & 0.722 \\
\hline & Wilks' Lambda & 0.974 & $0.515^{a}$ & 4.000 & 154.000 & 0.725 \\
\hline & Hotelling's Trace & 0.027 & 0.511 & 4.000 & 152.000 & 0.727 \\
\hline & Roy's Largest Root & 0.026 & $1.016^{\mathrm{C}}$ & 2.000 & 78.000 & 0.367 \\
\hline
\end{tabular}

The next step was to analyse whether or not was a difference between the groups defined by who the caller was in terms of physical detachment and closeness to communication partner. From the results shown in Table 6 below, it can be concluded that there is no significant difference between the groups defined by who the caller is in terms of perception of detachment from the physical surroundings $(p=0.178)$ and perception of closeness to the communication partner $(p=0.669)$.

\begin{tabular}{|c|l|c|c|c|c|c|}
\hline \multicolumn{2}{|c|}{ Table 6: Test of between-subjects effects (participants as call takers) } \\
\hline \multirow{2}{*}{ Source } & $\begin{array}{c}\text { Dependent } \\
\text { Variable }\end{array}$ & $\begin{array}{c}\text { Type III Sum of } \\
\text { Squares }\end{array}$ & $\mathrm{df}$ & $\begin{array}{c}\text { Mean } \\
\text { Square }\end{array}$ & $\mathrm{F}$ & Sig. \\
\hline \multirow{2}{*}{ RecCal } & DetPhys & 3.373 & 2 & 1.687 & 1.766 & 0.178 \\
\cline { 2 - 7 } & CloTal & 0.677 & 2 & 0.338 & 0.403 & 0.669 \\
\hline RecCal = calls received using mobile phones (participants as call takers) \\
\hline
\end{tabular}

The same analysis was conducted when the participants were call makers. Similar results were obtained, as shown in Table 7.

\section{Table 7: Test of between-subjects effects (participants as call makers)}

\begin{tabular}{|c|l|c|c|c|c|c|}
\hline Source & $\begin{array}{c}\text { Dependent } \\
\text { Variable }\end{array}$ & $\begin{array}{c}\text { Type III Sum of } \\
\text { Squares }\end{array}$ & df & $\begin{array}{c}\text { Mean } \\
\text { Square }\end{array}$ & F & Sig. \\
\hline \multirow{2}{*}{ MadCal } & DetPhys & 1.701 & 2 & 0.850 & 0.871 & 0.423 \\
\cline { 2 - 7 } & CloTal & 0.472 & 2 & 0.236 & 0.280 & 0.756 \\
\hline \multicolumn{7}{l}{ MadCal = calls made using mobile phones (participants as call makers) } \\
\hline
\end{tabular}

In summary, the findings corroborate the assumed spatial-temporal disjuncture that mobile phones provoke in the communicative environment as has been argued above. Most importantly, the results suggest that no matter whether young adults are call makers or call receivers and no matter who their communicative partners are, the perceptions of co-presence are similar.

\section{Discussion and Conclusion}

This is not a definite study but has already shed some light on the transient experience of mobile phones users across the space- time system. What has been demonstrated in this study is that, regardless of whether the participants are the call makers or the call takers, there are no differences between the different treatment groups (i.e., loving partners, close family members and friends) in terms of their perception of both physical detachment from the surroundings and their perception of personal closeness to the communication partner.

The evidence suggests that young adult users of mobile phones are creating their own social space-time system. The portability of mobile phones has made 
possible to overcome the limitations that landline phones impose on where and when phone communication could take place. The participants reported that they use their mobile phones while commuting - e.g., bus, train, ferry, car, bicycle, walking, etc. - and in both public places - e.g., restaurants, cafes, pubs, casinos, etc. - and private places - i.e., car and home, including bathroom. From different places at the time that suit them best, participants maintain their social interaction with those who they care the most; in this research, it was found they are their loving partners, close family members and friends. Interestingly enough, the vast majority of the responses deemed valid reflect the participants' agreement or strong agreement that their lives without a mobile phone would be a nightmare (81.5\%). Just $3.7 \%$ of them strongly disagreed or disagreed with this assertion; the rest (14.8\%) stated they remain neutral.

There is something that is worth noting here, which signals potential avenues for future research. The findings indicate that the participants consistently feel close to their communication partners and to some extent feel detached from their physical surrounding. The results of this repeatedmeasures analysis reveal that the perceived detachment from the physical surroundings $(M=3.57, S E=0.110)$ is significantly different than the perceived closeness to the communication partner $(\mathrm{M}=2.54, \mathrm{SE}=0.101)$, $t(80)=7.409, p<0.05 \quad(p=0.000)$, effect size $r=0.64$. This discovery reveals the tensions between being physically present at a specific location and feeling connected to those at a distance. It also reveals that young adults feel close to their communication partners at the other end of the line when they use their mobile phones, while simultaneously are to a certain extent mindful of people in their vicinity. In fact, when asked what topics they would avoid to talk about on their mobile phones in front of strangers, the most common answers were money and sex and, to a lesser extent, health and politics. This is a finding that deserves further examination, which may have implications on how mobile phone users relate to different physical experiences (e.g., retail, entertainment).

Exploring to what extent the now apparently ubiquitous social interaction across the space-time system enabled by mobile phones affects face-to-face interactions is another promising area of future research. On the one hand, Gergen (2002) argues that instead of negatively affecting personal interaction, mobile phones seem to have a revitalising effect because their affordances of keeping people perpetually connected and allowing coordination on the move. On the other hand, Turkle's (2012) TED talk describes how mobile phones engender an environment "to keep one another at distances we can control: not too close, not too far, just right". She calls it the "Goldilocks effect", by which individuals are more and more resorting to editable, technology-mediated communications as a substitute of untidy face-to-face conversations, with their unpredictable and spontaneous twists. Along similar lines, studies on instant message communication among adolescents suggest that the closeness of communication may lead to social anxiety and loneliness (cf. Gross et al., 2002).

Two limitations exist in this study. The first and primary limitation of this study is that only data about self-reported perceived copresence has been captured in the questionnaire. Future studies may benefit by including perceived others' copresence - cf. Nowak and Biocca (2003). The second limitation is only two variables have been used to measure co-presence: perceived closeness to the communication partner perceived physical detachment from the individual's physical surroundings Two variables that have not been included in this study and could enhance to our understanding of young adult's social life through mobile phones are interactivity and vividness. The former represents the history of interrelated messages between communicative partners (Rafaeli, 1988), while the former describes the richness of 
the technologically-created and -mediated environment and how it presents information to the individual (Steuer, 1992). However, researchers need to assess carefully the appropriateness of including vividness on mobile phone research because previous research has revealed the relative low degree of vividness of phone communication (Steuer, 1992).

Although more research needs to be conducted on the patterns of using mobile phones, and mobile computing devices in general, this study contributes to our understanding of how social life is transferred from physical co-location to perceived co-presence among young adults.

\section{Acknowledgements}

The author wishes to thank the two anonymous reviewers for their extensive and helpful comments. This research project was supported by the Auckland University of Technology- Tertiary Education Commission Summer Studentship (2009-2010).

\section{References}

Barker, C. (2003). Cultural studies: Theory and practice (2nd ed.). London, UK: Sage Publications.

Bassett, C. (2000). "In the company of strangers: User perceptions of the mobile phone." in Haddon, L. (ed.), Communications on the move: The experience of mobile telephony in the 1990s (COST [European Organisation for Cooperation in the field of Scientific and Technical Research] 248 Report (pp. 116-135). Tells, Norway: Farsta.

Benkler, Y. (2006). The wealth of networks: How social production transforms markets and freedom. New Haven, CT, USA: Yale University Press.

Campos-Castillo, C. and Hitlin, S. (2013). "Copresence: Revisiting a building block for social interaction theories". Sociological Theory, 31(2), 168-192.
Castells, M. (2000). The information age: Economy, society and culture - The rise of the network society (2nd ed., Vol. 1). Malden, MA, USA: Blackwell Publishing.

Castells, M., Fernández Ardèvol, M., Qiu, J. L. and Sey, A. (2007). Mobile communication and society: A global perspective. London, UK: The MIT Press.

Commerce Commission. (2013). 2012 Annual telecommunications monitoring report (3/May/2013). Wellington, New Zealand: Commerce Commission New Zealand.

comScore. (2007). "Consumers in the 18-24 age segment view cell phones as multi-functional accessories." Retrieved 18/March, 2010, from http://www.comscore.com/Press Ev ents/Press Releases/2007/01/Cell Phones and 18-24 Year Olds

Cooper, G. (2002). "The mutable mobiles: Social theory in the wireless world." in Brown, B., Green, N. and Harper, R. (eds.), Diaper, D. and Sanger, C., Wireless World: Social and Interactional Aspects of the Mobile Age (pp. 19-31). London, UK: Springer-Verlag.

Dubinskas, F. A. (Ed.). (1988). Making time: Ethnographies of high-technology organizations. Philadelphia, PA, USA: Temple University Press.

Field, A. (2009). Discovering statistics using SPSS (3rd ed.). London, UK: Sage.

Fortunati, L. (2005). "Mobile telephone and the presentation of self." in Ling, R. and Pedersen, P. E. (eds.), Mobile communications: Re-negotiation of the social sphere (pp. 203-218). London, UK: Springer.

García-Montes, J. M., Caballero-Muñoz, D. and Pérez-Alvarez, M. (2006). "Changes in the self resulting from 
the use of mobile phones". Media, Culture \& Society, 28(1), 67-82.

Gergen, K. J. (2002). "The challenge of absent presence." in Katz, J. E. and Aakhus, M. A. (eds.), Perpetual contact: Mobile communication, private talk, public performance (pp. 227-241). Cambridge, UK: Cambridge University Press.

Gibbins, J. R. and Reimer, B. (1999). The politics of postmodernity: An introduction to contemporary politics and culture. London, UK: Sage Publications.

Gibbs, N. (2012, 27 August). Your life is fully mobile. Time, 180(9), 30-37.

Giddens, A. (1984). The constitution of society. Cambridge, UK: Polity Press.

Giddens, A. (1990). The consequences of modernity. Cambridge, UK: Polity Press.

Gillespie, A. and Williams, H. (1988). "Telecommunications and the reconstruction of regional comparative advantage". Environment and Planning A, 20(10), 1311-1321.

Goffman, E. (1971). The presentation of self in everyday life. Harmondsworth, UK: Penguin.

Green, N. (2002). "On the move: Technology, mobility, and the mediation of social time and space". The Information Society, 18(4), 281292.

Gross, E. F., Juvonen, J. and Gable, S. L. (2002). "Internet use and well-being in adolescence". Journal of Social Issues, 58(1), 75-90.

Haddon, L. (2005). "Research questions for the evolving communications landscape." in Ling, R. and Pedersen, P. E. (eds.), Diaper, D. and Sanger, C., Mobile communications: Re-negotiation of the social space (pp. 7-23). London, UK: Springer-Verlag.

Hair Jr., J. F., Anderson, R. E., Tatham, R. L. and Black, W. C. (1998). Multivariate data analysis (5th ed.). Upper Saddle River, NJ, USA: Prentice Hall.

Harvey, D. (1990). The condition of postmodernity: An enquiry into the conditions of cultural change. Oxford, UK: Blackwell.

Harvey, D. (1993). "From place to space and back again: Reflections on the condition of postmodernity." in Bird, J., Curtis, B., Putnam, T., Robertson, G. and Tickner, L. (eds.), Mapping the futures: Local cultures, global change. London, UK: Routledge.

Hawking, S. and Mlodinow, L. (2005). A briefer history of time. London, UK: Bantam Press.

ljsselsteijn, W. A. and Riva, G. (2003). "Being there: The experience of presence in mediated environments." in Riva, G., Davide, F. and ljsselsteijn, W. A. (eds.), Being there: Concepts, effects and measurement of user presence in synthetic environments (pp. 3-14). Amsterdam, The Netherlands: Ios Press.

International Telecommunication Union. (2013). The world in 2013: ICT facts and figures. Retrieved 26/September, 2013 http://www.itu.int/en/ITUD/Statistics/Documents/facts/ICTFac tsFigures2013.pdf

Ito, M. (2005). "Mobile phones, Japanese youth, and the re-placement of social contact." in Ling, R. and Pedersen, P. E. (eds.), Diaper, D. and Sanger, C., Mobile communications: Re-negotiation of the social sphere (pp. 131-148). London, UK: Springer-Verlag.

Katz, J. E. and Aakhus, M. A. (Eds.). (2002). Perpetual contact: Mobile 
communication, private talk, public performance. Cambridge, UK: Cambridge University Press.

Katz, J. E. and Sugiyama, S. (2005). "Mobile phones as fashion statements: The co-creation of mobile communication's public meaning." in Ling, R. and Pedersen, P. E. (eds.), Mobile communications: Re-negotiation of the social sphere (pp. 63-81). London, UK: SpringerVerlag.

Kennedy, P. (1998). A guide to econometrics (4th ed.). Cambridge, MA, USA: The MIT Press.

Ling, R. (2000). "'We will be reached": The use of mobile telephony among Norwegian youth". Information Technology and People, 13(2), 102120.

Lombard, M. and Ditton, T. (1997). "At the heart of it all: The concept of presence". Journal of ComputerMediated Communication, 3(2).

Middleton, C. A. (2007). "Illusions of balance and control in an always-on environment: A case study of Blackberry users." Retrieved 7/April, 2011, from http://digitalcommons.ryerson.ca/trist $\underline{\mathrm{m} / 4}$

Norris, P. (2001). "The accidental president: Fuzzy math, Florida lawsuits, and campaign 2000". Journal of Elections, Public Opinion \& Parties, 11(1), 174-191.

Nowak, K. L. and Biocca, F. (2003). "The effect of the agency and anthropomorphism on users' sense of telepresence, copresence, and social presence in virtual environments". Presence, 12(5), 481-494.

Ogden, M. R. (1994). "Politics in a parallel universe: Is there a future for cyberdemocracy?". Futures, 26(7), 713-729.
Plant, S. (2002). "On the mobile: The effects of mobile telephones on social and individual life." Retrieved 21/August, 2010, from http://www.motorola.com/mot/doc/0/ 234 MotDoc.pdf

Rafaeli, S. (1988). "Interactivity: From new media to communication." in Hawkins, R. P., Wieman, J. M. and Pingree, S. (eds.), Advancing communication science: Merging mass and interpersonal processes (pp. 110-134). Newbury Park, CA, USA: Sage.

Rheingold, H. (2002). Smart mobs: The next social revolution. Cambridge, MA, USA: Perseus Publishing.

Riva, G. and Mantovani, G. (2000). "The need for a socio-cultural perspective in the implementation of virtual environments". Virtual Reality, 5(1), 32-38.

Schegloff, E. A. (2002). "Beginnings in the telephone." in Katz, J. E. and Aakhus, M. A. (eds.), Perpetual contact: Mobile communication, private talk, public performance (pp. 284-300). Cambridge, UK: Cambridge University Press.

Schubert, T., Friedmann, F. and Regenbrecht, H. (2001). "The experience of presence: Factor analytic insights". Presence: Teleoperators \& Virtual Environments, 10(3), 266-281.

Statistics NZ. (2010). Household use of information and communication technology: 2009. Wellington, New Zealand: Statistics New Zealand.

Statistics NZ. (2013). Household use of informatin and communication technology: 2012. Wellington, New Zealand: Statistics New Zealand.

Steuer, J. (1992). "Defining virtual reality: Dimensions determining telepresence". Journal of Communication, 42(4), 73-93. 
Toffler, A. (1971). Future shock. London, UK: Pan Books.

Turkle, S. (2011). Alone together: Why we expect more from technology and less from each other. New York, NY, USA: Basic Books.

Turkle, S. (2012). "Connected, but alone?." Retrieved 28/July, 2012, from http://www.ted.com/talks/sherry turkl e alone together.html

van Bijljon, J., Kotzé, P. and Renaud, K. (2008, 8-12 December). "Mobile phone usage of young adults: The impact of motivational factors." Proceedings of the Australasian Computer-Human Interaction Conference, Cairns, QLD, Australia.

Weilenmann, A. and Larsson, C. (2002). "Local use and sharing of mobile phones." in Brown, B., Green, N. and Harper, R. (eds.), Wireless world: Social and interactional aspects of the mobile age (pp. 92107). London, UK: Springer-Verlag.

Wellman, B., Quan-Haase, A., Boase, J., Chen, W., Hampton, K., Isla de Díaz, I. and Miyata, K. (2003). "The social affordances of the Internet for networked individualism". Journal of Computer-Mediated Communication, 8(3), 1-43.

Zhao, Z. (2003). "Toward a taxonomy of copresence". Presence, 12(5), 445455.

\section{About the Author}

Antonio Díaz Andrade is a Senior Lecturer in Business Information Systems at Auckland University of Technology, New Zealand. He has a strong interest in the interplay between the social and the technical, especially in the area of information and communication technology for development. 